\title{
A geographical information system-based web model of arbovirus transmission risk in the continental United States of America
}

\author{
Sarah K. Konrad, Li Zou, Scott N. Miller \\ University of Wyoming, Ecosystem Science and Management, Dept. 3354 Laramie, WY 82071, USA
}

\begin{abstract}
A degree-day (DD) model of West Nile virus capable of forecasting real-time transmission risk in the continental United States of America up to one week in advance using a 50-km grid is available online at https://sites. google.com/site/arbovirusmap/. Daily averages of historical risk based on temperatures for 1994-2003 are available at 10$\mathrm{km}$ resolution. Transmission risk maps can be downloaded from 2010 to the present. The model can be adapted to work with any arbovirus for which the temperature-related parameters are known, e.g. Rift Valley fever virus. To more effectively assess virus establishment and transmission, the model incorporates "compound risk" maps and forecasts, which includes livestock density as a parameter.
\end{abstract}

Keywords: West Nile virus, Rift Valley fever virus, transmission risk, early warning system, United States of America.

Link: http://www.geospatialhealth.unina.it/vHealth/gh-v7i1-konrad-01

\section{Background}

A geographical information system (GIS)-based model which uses degree-day (DD) temperatures to identify regions and times of West Nile virus (WNV) transmission risk has been successfully tested in Wyoming, California, Montana, South Carolina and Connecticut (Zou et al., 2007; Konrad et al., 2009; Schrag et al., 2011; Konrad and Miller, 2012b). Here, we adapt the model to a web-platform allowing Internet users the ability to observe risk both in forecast mode and from the viewpoint of historical transmission. This model (https://sites.google.com/site/arbovirusmap/) is based upon the premise that a mosquito, even when infected with a virus, cannot transmit the virus unless it is present in the mosquito's salivary glands (Hardy et al., 1983). The rate at which the virus disseminates from the mosquito gut to its salivary glands is controlled by the ambient temperature (Dohm et al., 2002; Reisen et al., 2006). If the temperature is sufficiently high, a mosquito taking an infected blood meal will become transmissive while still feeding; conversely, if it is too cold during feeding, an infected mosqui-

\section{Corresponding author:}

Sarah K. Konrad

University of Wyoming, Ecosystem Science and Management

Dept. 3354, Laramie, WY 82071, USA

Tel. +1 307766 2295; Fax +1 3077666403

E-mail: skonrad@uwyo.edu to will not be able to transmit the virus.

Model inputs were temperature-based parameters, calibrated to fit WNV transmission observations in the United States of America (USA), length of the vector's feeding period (assuming 12 days, according to Reisen et al., 1993) and daily maximum and minimum temperatures for each day of the feeding period. DD temperatures were calculated by assuming a sinusoidal curve between the maximum and minimum temperatures after Allen (1976). Temperature data (http://www.cpc.ncep.noaa.gov/products/ GIS/GIS_DATA/) and temperature forecast data (http://www.nws.noaa.gov/ndfd/technical.htm) were downloaded daily from the National Oceanic and Atmospheric Administration (NOAA) (http:// www.noaa.gov/) on a $50-\mathrm{km}$ grid of the contiguous USA. The NOAA temperature data forecast is available 7 days out; therefore forecast DDs were combined with actual DDs in order to forecast the transmission risk. For example, on June 16 of any year we forecast risk on June 22 by adding seven forecast DDs (June 16-22) to five actual DDs (June 11-15) arriving at a total of 12 days representing the vector feeding period from 11 to 22 June. To forecast transmission risk on June 21, we used 6 days of actual data and 6 days of forecast data; thus the accuracy of the transmission risk forecast is higher for dates closer to the present day. An overview of the most recent forecast risk map is available online; daily risk maps and forecast risk maps from January 1, 2010 to 6 days after the present 
day are available for download and can be viewed interactively as a layer using GIS software that supports TIFF files.

To provide historical risk assessment, we created daily risk maps based on the average of temperatures over a 10-year period from January 1, 1994 to December 31, 2003. These risk maps were designed to provide a relatively recent standard, with which to compare current risk predictions. The data fed into the model consisted of temperatures for the historical risk, downloaded from DAYMET (http://daymet.ornl.gov/; Thornton et al., 1997) on a $10-\mathrm{km}$ grid of the contiguous USA for each day of the 10-year period and compiled to produce an average temperature maximum and minimum for each day of the year at every grid point. The DAYMET data were taken from a complex interpolation scheme, which generates temperatures over a much finer grid than that available from NOAA. Users of the website will notice the different scales of the risk assessments when comparing the historical data with current observations and forecasts.

The DD model can be adapted to describe transmission risk of other arboviruses as well, e.g. Rift Valley fever virus (RVFV) as show by Konrad et al. (2011) and Konrad and Miller (2012a). Since RVFV has not appeared in USA, field calibration with North American mosquitoes is not currently possible. Laboratory work with captive-raised populations of North American mosquitoes exposed to RVFV has so far failed to provide a conclusive temperature relationship. In the absence of data, it is reasonable to use the WNV parameters to describe the risk of RVFV transmission (MJ Turell, personal communication).

Two types of risk maps are available on the website: temperature-based and compound ones. The temperature-based risk can be used to estimate the transmission risk of either WNV or RVFV; whereas the compound risk is specifically designed to observe an additional risk factor related to RVFV, i.e. the presence of a livestock reservoir. As domestic livestock are the primary virus reservoir in African countries, where RVFV is endemic, we assumed that RVFV will be more likely to become established in regions of the USA that support a relatively high livestock population. The DD temperature assessment alone reflects the risk of RVFV transmission, while combining these results with livestock density identifies regions where the chance of the establishment of RVFV is high. This combinatorial approach also identifies those areas where establishment of the virus will have greater potential economic impact on the livestock industry.
Compound risk is assessed by normalizing both the number of accumulated DDs above the transmission threshold and the livestock density on linear scales. These results are then summed and mapped onto a relative-risk scale. If the accumulated DDs do not exceed the threshold temperature, the compound risk will also be assumed to be zero. Censuses taken in 2002 and 2007 by the United States Department of Agriculture National Agricultural Statistics Service (USDA-NASS) (http://www.nass.usda.gov) provided the livestock data. We calculated livestock densities at the county level by summing together cattle-calf, sheep-lamb and goat populations (the most common RVFV hosts). In the few cases where population numbers for specific counties were withheld to protect privacy, we back-calculated the populations by apportioning the state total across the unreported counties in proportion to the number of farms in each county. The 2002 data were used to calculate the historical compound risk, and the 2007 data were used for the forecast and more recent compound risk (2010 to present).

\section{Outlook}

The use of actual and forecast temperatures in the model, predicting when and where WNV transmission is possible, provides a powerful tool that can assist with pre-emptive mosquito control measures and proactive warnings to the public. Its greatest value is in predicting the onset of the "risk season" rather than the end of transmission risk as temperatures decline in the autumn. It can be easily adapted to fit other arboviruses if temperature-based parameters become available. However, the model does not take in to account all elements necessary for virus transmission (e.g. the population and/or presence of vectors and hosts), and should not be the only tool used by vector control districts.

\section{Acknowledgements}

This project was funded by the United States Department of Agriculture specific cooperative agreement \#5410-32000-01415 .

\section{References}

Allen JC, 1976. A modified sine wave method for calculating degree-days. Environ Entomol 5, 388-396.

Dohm DJ, O’Guinn ML, Turell MJ, 2002. Effect of environmental temperature on the ability of Culex pipiens (Diptera: Culicidae) to transmit west Nile virus. J Med Entomol 39, 
221-225.

Hardy JL, Houk EJ, Kramer LD, Reeves WC, 1983. Intrinsic factors affecting vector competence of mosquitoes for arboviruses. Ann Rev Entomol 28, 229-262.

Konrad SK, Miller SN, 2012a. A temperature-limited assessment of the risk of Rift Valley fever transmission and establishment in the continental United States. Geospat Health 6, 161-170.

Konrad SK, Miller SN, 2012b. Application of a degree-day model of West Nile virus transmission risk to the East Coast of the United States. Geospat Health 7, 15-20.

Konrad SK, Miller SN, Reeves WK, 2011. A spatially explicit degree-day model of Rift Valley fever transmission risk in the continental United States. GeoJournal 76, 257-266.

Konrad SK, Miller SN, Reeves WK, Tietze NS, 2009. Spatially explicit West Nile virus risk modeling in Santa Clara County, CA. Vector Borne Zoonotic 9, 267-274.
Reisen WK, Fang Y, Martinez VM, 2006. Effects of temperature on the transmission of West Nile virus by Culex tarsalis (Diptera: Culicidae). J Med Entomol 43, 309-317.

Reisen WK, Meyer RP, Presser SB, Hardy JL, 1993. Effect of temperature on the transmission of western equine encephalomyelitis and St. Louis encephalitis viruses by Culex tarsalis (Diptera: Culicidae). J Med Entomol 30, 151-160.

Schrag AM, Konrad SK, Miller SN, Walker BL, Forrest SC, 2011. Climate-change impacts on sagebrush habitat and West Nile virus transmission risk and conservation implications for greater sage grouse. GeoJournal 76, 561-575.

Thornton PE, Running SW, White MA, 1997. Generating surfaces of daily meteorology variables over large regions of complex terrain. J Hydrol 190, 214-251.

Zou L, Miller SN, Schmidtmann, ET, 2007. A GIS tool to estimate West Nile virus risk based on a degree-day model. Environ Monit Assess 129, 413-420. 